\title{
Seroprevalence of brucella infection among pregnant women in Sana'a city, Yemen
}

\begin{abstract}
Introduction: Brucellosis is a leading cause of zoonosis worldwide caused by the bacterial genus. Brucella that transmitted to humans via either, direct or indirect contact with infected animals or their products. Yemeni pregnant women are not routinely tested for Brucellosis. There is no published data concerning brucella seroprevalence during pregnancy. Therefore the aims of our study were to determine the seroprevalence associated risk factors of brucella infection among pregnant women in Sana'a city, Yemen.
\end{abstract}

Materials and methods: A descriptive cross-sectional study was carried out in some hospitals and clinical health centers in Sana'a city, Yemen from June to August 2016 in order to assess the seroprevalence of brucella IgM and IgG antibodies to brucella among pregnant women by using enzyme-linked immunosorbent assay (ELISA) kits. The serum sample was collected from 304 pregnant women who attended the antenatal clinic in some hospitals and health centers in Sana'a city. Before collection of sample, questionnaires were revolved to the pregnant women to obtain data on sociodemographics, obstetric characteristic, risk factors and clinical symptoms associated with brucella infection

Results: Of the 304 pregnant women, 42(13.82\%) and 17(5.95\%) were positive for antibrucella IgM and IgG antibodies, respectively. Urban erea observed significance with anti-brucella IgM seropositive antibodies and also a significant association was found with headache (IgG, $\mathrm{P}=0.01)$ and undulant fever $(\operatorname{IgM}, \mathrm{P}=0.02)$ for brucella $\operatorname{IgG}$ and IgM antibodies respectively. All of the possible risk factors studied and reproductive characteristics were not significantly associated with infection (P-value $>0.05)$.

Conclusion: The overall seroprevalence of brucella antibodies was high. This is suggest $\rightarrow$ ing that a sustained infection in the Yemeni population and indicating endemicity. Adoption of brucella screening into the antenatal profile tests is recommended. Advance study intended to compare all provinces in the country for brucella seroprevalence in order to get a comprehensive information of the problem is recommended.

Keywords: seroprevalence, brucella, risk factors pregnant women, ELISA, Sana'a, Yemen
Special Issue - 2018

\author{
Qais Y M Abdullah, Salwa H Alkhyat, Anas \\ A Almahbashi, Mofeed Al-Nowihi,Assem \\ Al-Thobahni, Mohammed N Q Al-Bana, Saad \\ Al-Arnoot \\ Department of Biology, Sana'a University, Yemen
}

Correspondence: Saad Al-Arnoot, Microbiology Branch, Department of Biology, Faculty of Science, Sana'a University, Sana'a, Yemen, Tel 00967774667900 , Email saad.alarnoot@gmail.com

Received: July 27, 2017| Published: September 28, 2018

\section{Introduction}

Brucellosis, commonly known as "undulant fever", "Mediterranean fever" or "Malta fever" is a leading cause of zoonosis worldwide caused by the bacterial genus brucella. ${ }^{1}$ Brucella is an aerobic, gram-negative, non-fermenting, facultative intracellular, non-motile, non-spore-forming, cocci, cocobacilli or short rods based on DNA homology and represent a single species. ${ }^{2,3}$ It is transmitted to humans by direct or indirect contact with infected animals or their products. ${ }^{1-5}$ The entry of the organism is the conjunctiva, respiratory mucosa and damaged skin. ${ }^{6}$ Generally the transmission from person to person is uncommon, however the human sources of infection may occur in the following ways: vertical transmission with placental circulation, breast feeding, sexual contact, blood transfusion and bone marrow transplantation.?

The most common reported symptoms and signs were fever, headaches, fatigue, malaise, chills, sweats, myalgia, lack of appetite, weight loss and arthralgia. ${ }^{8-11}$ The first reported brucellosis during pregnancy was in 1908 when (Malta fever), brucellosis, was clinically described. ${ }^{12}$ Lately, spontaneous abortions in women might be associated with the isolation of brucella from an aborted fetuses placenta. ${ }^{13,14}$ It is believed that brucellosis causes fewer spontaneous abortions in humans than it does in animals because of the absence of erythritol in the human placenta and fetus. ${ }^{15}$ Erythritol is a constituent of normal ungulate fetal and placental tissue and, in cases of bovine abortion, promotes overwhelming infection of the fetus and placenta. Additionally, the reason for the lesser role of abortion in human brucellosis is the presence of anti-brucella activity in human amniotic fluid. ${ }^{13}$

Brucellosis is an endemic disease in the south and central Asia, Middle East, north and east Africa, Mediterranean countries of Europe, and South America. The reported incidence of human brucellosis in endemic disease areas varies widely, from $<0.01$ to $>200$ per 100,000 population. ${ }^{4}$ Nevertheless, in most countries the incidence of human brucellosis is unknown and it has been estimated that the incidence may be 25 times higher than the reported incidence due to underreporting or misdiagnosis. ${ }^{16}$ In Yemen the seroprevalence of human brucellosis was ranging from 0.3 to $32.3 \%{ }^{17}$ which remains a major endemic health problem, but there is no published data concerning brucella seroprevalence during pregnancy. So, the aim of this present 
study was to determine associated risk factors and the prevalence of human brucellosis among pregnant women in Sana'a city, Yemen. It should be performed to contribute in establishing primary database of brucella incidence and prevalence in Yemen. This basic data concerning brucella infection in pregnancy is significant for health planners and care providers.

\section{Materials and methods}

\section{Study area}

This study was conducted in Sana'a city. It is the capital of Yemen, located on northern part of the country. It is considered as the largest city in Yemen in terms of population according to the last population enumeration in 2004 which is 1,7476,834 (940585 males, 766728 females and 93157 children below 15years old), but the number of population might be increased because of emigration to Sana'a as a result of civil war. Six main hospitals and health centers in Sana'a city were chosen as sample collection centers.

\section{Study population and study design}

A descriptive cross-sectional study was conducted among 304 pregnant women attending antenatal clinic in some hospitals and health centers in Sana'a city, Yemen during the period between June to August 2016. Inclusion criteria for enrollment in the study were:

i. Pregnant women

ii. Residing in Sana'a city

iii. Aged 15 years and older and

iv. Who accepted to participate in the study

Calculation of the sample size was performed with the aid of the Epi Info version 7 software, we used a value of 766728 as a population size from which the sample was selected, a reference seroprevalence of $24.40 \%{ }^{18}$ as expected frequency of the factor under study, $5 \%$ of confidence limits, a design effect of 1.0, one cluster, and a confidence level of $95 \%$. The result of the calculation was 283 subjects.

\section{Data collection}

The questionnaire was designed to collect information regarding socio-demographics, reproductive and obstetrical characteristics, clinical symptoms, and risk related data. It was designed according to many previous studies ${ }^{19-21}$ with slight modification to suit this study. The questionnaire was first developed in English and translated into Arabic language in order to be easy for investigators who helped to fill it in some cases. Most of the questions were "Yes or No" type and took about 5 minutes to complete the questionnaire.

Sample collection, handling and storage: After getting oral and written informed consent from the participants, about (Five-ml) blood sample was collected from each consenting subject by venipuncture, transferred into anticoagulant-free sterile bottle, and allowed to clot. Then centrifuged (3000rpm, 5min), and the serum was transferred into cryovials. The serum sampled from every subject participating in the study was placed in two separate eppendrof tubes. One was referred to as the original sample and the second was referred to as the backup sample. This was done to avoid repeated freezing/ thawing cycles (which were kept to a minimum) or an insufficient quantity of serum. The second sample was used as a backup sample in case anything went wrong with the original one or its quantity was insufficient. Serum samples were stored at -10 to $-20^{\circ} \mathrm{C}$. These samples were stored in different freezers placed in two different locations that both had a backup electricity supply in case there were any power failures and were checked every day, once in the morning and once at night. Twenty-four hours prior to performing the first serological assay, samples were taken out of the freezer and placed in a refrigerator at $4{ }^{\circ} \mathrm{C}$ overnight. After samples were allowed to thaw in a refrigerator overnight they were removed from the refrigerator early in the morning for performing the serological assay.

\section{Serologic testing}

The serum samples were analyzed for Brucella $\operatorname{IgG}$ and $\operatorname{IgM}$ by using enzyme-linked immunosorbent assay commercial diagnostic kits (Nova Tec Immundiagnostica GmbH, Germany). These assays were used according to the manufacturer's instructions. The reading of these results which obtained in this study were read by a microplate reader (Mindray MR-96A; Shenghen Mindray Bio Medical Electronics Com Ltd, Germany) and compared in a parallel manner with the calibrator and controls. All samples that were equal to or higher than index of 10 were interpreted as positive. The whole samples with an index of $<9$ were interpreted as negative, and those with an index of 9-10 were equivocal. The controls and the calibrators passed the validation check recommended by the manufacturer of the kit.

\section{Ethical consideration}

The ethical of this research was granted by Biology Department, Faculty of Sciences, Sana'a University ethical committee after due process had been followed. Before, the collection of sample, questionnaire of this study was explained to the all women. Confidentiality was assured by using numbers instead of names. Moreover, oral and written consent for participation in the study was obtained.

\section{Statistical analysis}

The data entered and analysis was by using SPSS version 21, and reduced to percentiles and figures. The Pearson $\chi 2$ test at a $95 \%$ confidence interval and a significance level of 0.05 was used to determine the relationships between the data collection and seroprevalence rates. $P$ values of 0.05 or less was considered to be significant.

\section{Results}

About 304 subjects were enrolled in the study which range from 15 to 40years old with mean age of pregnant women was $25.25(\mathrm{SD}=4.98)$ years. Out of 304 subjects 179 were $<25$ years old, while 121 of them were illiterate or have basic education. Most of the subjects, 292(96.05\%) lived in urban area and all almost of them were housewife. Our results showed that the seroprevalence of $5.95 \%(17$ of 304 ) and $13.82 \%$ (42 of 304) for brucella IgG and IgM antibodies, respectively, among pregnant women. Of the $42(13.81 \%)$ pregnant women were positive for brucella IgM antibody, 14(4.6\%) were also positive for brucella-specific IgG antibody while out of the remaining $28(9.21 \%)$ pregnant women that were positive for brucella IgM antibody, 3(0.98\%) were positive for brucella IgG antibody and the remaining $259(85.19 \%$ ) were negative for both $\operatorname{IgM}$ and $\operatorname{IgG}$ antibodies. 
Among the socio demographic variables, only residence of urban erea observed a significant association with anti- brucella IgM seropositive antibody, however other variables like age, education level and occupation were not associated (Table 1). The most common reproductive characteristics, such as the parity, trimester, preterm delivery, cesarean sections, spontaneous abortions, stillbirths, and malformed children were studied (Table 2). Nearly half of the subject $(44.41 \%)$ were in their first trimester. $26(8.55 \%)$ of the subjects have more than four children, 16(5.26\%), 99(32.57\%), 24(7.89\%), $28(9.21 \%)$ and $6(1.97 \%)$ of the pregnant women had a history of abortion, cesarean sections, stillbirth, and malformed children, respectively.

Table I Seroprevalence of brucella $\lg M$ and $\lg G$ antibodies among pregnant women according to socio-demographical characteristics

\begin{tabular}{|c|c|c|c|c|c|}
\hline \multirow{2}{*}{ Category } & \multirow{2}{*}{$\begin{array}{l}\text { Participants } \\
\text { No. (\%) }\end{array}$} & \multicolumn{2}{|c|}{ IgG positive } & \multicolumn{2}{|c|}{ IgM positive } \\
\hline & & No. (\%) & $\begin{array}{l}P \text { - } \\
\text { Value }\end{array}$ & No. (\%) & $\begin{array}{l}P \text { - } \\
\text { Value }\end{array}$ \\
\hline \multicolumn{6}{|l|}{ Age } \\
\hline $15-25$ & 179(58.88) & $10(5.59)$ & & $22(12.29)$ & \\
\hline $26-35$ & $113(37.17)$ & $6(5.31)$ & 0.91 & $20(17.70)$ & 0.16 \\
\hline $36-45$ & $12(3.95)$ & $I(8,38)$ & & $0(0.00)$ & \\
\hline \multicolumn{6}{|l|}{ Residence } \\
\hline Rural & $91(29.93)$ & $3(3.30)$ & & $7(7.69)$ & \\
\hline Urban & $213(70.07)$ & 14(6.57) & 0.25 & $35(16.43)$ & $0.04 *$ \\
\hline \multicolumn{6}{|c|}{ Education level } \\
\hline Illiterate & $50(16.45)$ & $0(0.00)$ & & $4(8.00)$ & \\
\hline Basic & $71(23.36)$ & $7(9.86)$ & & $10(14.08)$ & \\
\hline Primary & $47(15.46)$ & $5(10.64)$ & 0.07 & $8(17.02)$ & 0.72 \\
\hline Secondary & $93(30.59)$ & $4(4.30)$ & & $13(13.98)$ & \\
\hline University & $43(14.14)$ & $\mathrm{I}(2.33)$ & & $7(16.28)$ & \\
\hline \multicolumn{6}{|c|}{ Occupation } \\
\hline \multirow[t]{2}{*}{$\begin{array}{l}\text { House } \\
\text { wife }\end{array}$} & $292(96.05)$ & $17(5.82)$ & & $4 I(14.04)$ & \\
\hline & & & 0.39 & & 0.57 \\
\hline Employee & $12(3.95)$ & $0(0.00)$ & & $\mathrm{I}(8.33)$ & \\
\hline
\end{tabular}

Table 2 Distributions of brucella $\lg M$ and $\lg G$ antibodies among pregnant women according to their reproductive and obstetrical characteristics

Reproductive Participants IgG positive IgM positive

\& obstetrical P- $P_{-} \quad P_{-}$

\begin{tabular}{lllll}
\hline No. (\%) & No. (\%) & $\begin{array}{l}\text { P- } \\
\text { Value }\end{array}$ & No. (\%) & $\begin{array}{l}\text { P- } \\
\text { Value }\end{array}$ \\
\hline
\end{tabular}

\section{Trimester}

First

135(44.4I)

6(4.44) $\quad 0.74$

17(12.59)

0.81

Second

93(30.59)

6(6.45)

13(13.98)

Third

76(25.00)

5(6.58)

I2(I5.79)

Parity

None

98(32.24)

4(4.08) $\quad 0.69$

I4(I4.29) $\quad 0.09$

One to four

180(59.21)

II (6.II)

28(I5.56)

$>$ four

26(8.55)

2(7.69)

$0(0.00)$

Preterm deliveries

Yes

16(5.26)

$0(0.00)$

0.32

$0(0.00)$

0.09

No

288(94.74)

17(5.90)

42(14.58)

History of abortion

$\begin{array}{llllll}\text { Yes } & 99(32.57) & 5(5.05) & 0.77 & \mathrm{II}(\mathrm{II} . \mathrm{II}) & 0.34\end{array}$

No

205(67.43)

12(5.85)

$3 I(15.12)$

History of cesarean sections

$\begin{array}{llllll}\text { Yes } & 24(7.89) & I(4.17) & 0.75 & 4(16.67) & 0.67 \\ \text { No } & 280(92.1 I) & 16(5.7 I) & & 38(13.57) & \end{array}$

History of stillbirths

$\begin{array}{llllll}\text { Yes } & 28(9.2 I) & 0(0.00) & 0.18 & I(3.57) & 0.09 \\ \text { No } & 276(90.79) & I 7(6.16) & & 4 I(14.86) & \end{array}$

Malformed children

$\begin{array}{llllll}\text { Yes } & 6(1.97) & 0(0.00) & 0.54 & I(16.67) & 0.83 \\ \text { No } & 298(98.03) & 17(5.7) & & 4 I(13.76) & \end{array}$

More than half of the subject had anorexia, pain muscles, pain back, coldness, headache, fatigue and cold. Out of this pregnant women, 140(46.05\%), 130(42.76\%), 120(39.47\%), $13143.09 \%), 85(27.96 \%)$ and $38(12.5 \%)$ had fever, undulant fiver, weight loss, pain head back, sweaty and delirium, respectively, at the period of study. There were significant association with headache and undulant fever and the seropositivity for brucella $\operatorname{IgG}$ and $\operatorname{IgM}$ antibodies respectively (Table 4). Being brucellosis is zoonotic disease, situations that involve or result in contact with infected animals were considered to be as possible risk factors in this study (for example, occupation type, place of residence and polygamy) (Table 3 ). All the possible risk factors in this study were not significant $(P$-value $>0.05)$.

Table 3 Seroprevalence of brucella IgM and IgG antibodies among pregnant women according to risk factors

\begin{tabular}{llllll}
\hline Risk factors & \multicolumn{2}{c}{ Participants } & IgG positive & & IgM positive \\
\cline { 2 - 5 } & No. (\%) & No. (\%) & P-Value & No.(\%) & P-Value \\
\hline Animals at home & & & & \\
Yes & $107(35.20)$ & $6(5.6 I)$ & 0.99 & $1 \mathrm{I}(10.28)$ & 0.19 \\
No & $197(64.80)$ & $\mathrm{II}(5.58)$ & $3 \mathrm{I}(15.74)$ & \\
\hline
\end{tabular}


Table Continued...

\begin{tabular}{|c|c|c|c|c|c|}
\hline \multirow{2}{*}{$\begin{array}{l}\text { Risk factors } \\
\text { Milking anima }\end{array}$} & \multirow[t]{2}{*}{ Participants } & \multicolumn{2}{|l|}{ IgG positive } & \multicolumn{2}{|c|}{ IgM positive } \\
\hline & & & & & \\
\hline Yes & $36(11.84)$ & $2(5.56)$ & 0.99 & $2(5.56)$ & 0.12 \\
\hline No & $268(88.16)$ & $15(5.60)$ & & $40(14.93)$ & \\
\hline \multicolumn{6}{|c|}{ Contact with animal's newborn } \\
\hline Yes & $27(8.88)$ & $\mathrm{I}(3.70)$ & 0.65 & $\mathrm{I}(3.70)$ & 0.11 \\
\hline No & $277(91.12)$ & 16(5.78) & & $4 I(14.80)$ & \\
\hline \multicolumn{6}{|c|}{ Touch a fresh meat } \\
\hline Yes & 283(93.09) & $15(5.30)$ & 0.41 & $37(13.07)$ & 0.17 \\
\hline No & $21(6.91)$ & $2(9.52)$ & & $5(23.81)$ & \\
\hline \multicolumn{6}{|l|}{ Fresh milk } \\
\hline Yes & $91(29.9)$ & $8(47.1)$ & 0.11 & $10(23.8)$ & 0.35 \\
\hline No & $213(70.1)$ & $9(52.9)$ & & $32(76.2)$ & \\
\hline \multicolumn{6}{|c|}{ Raw liver and spleen } \\
\hline Yes & $8(2.63)$ & $0(0.00)$ & 0.48 & $0(0.00)$ & 0.25 \\
\hline No & 296(97.37) & $17(5.74)$ & & $42(14.19)$ & \\
\hline \multicolumn{6}{|l|}{ Yogurt } \\
\hline Yes & $178(58.55)$ & $10(5.62)$ & 0.98 & $21(11.80)$ & 0.22 \\
\hline No & $126(4 \mid .45)$ & $7(5$. & & $21(16.67)$ & \\
\hline \multicolumn{6}{|c|}{ Is there anyone at home as butcher? } \\
\hline Yes & $8(2.63)$ & $\mathrm{I}(12.50)$ & 0.39 & $\mathrm{I}(12.50)$ & 0.91 \\
\hline No & $296(97.37)$ & $16(5.41)$ & & $4 \mathrm{I}(13.58)$ & \\
\hline \multicolumn{6}{|c|}{ Is there anyone at home as farmer? } \\
\hline Yes & $36(11.84)$ & $0(0.00)$ & 0.12 & $2(5.56)$ & 0.13 \\
\hline No & $268(88.16)$ & $17(6.34)$ & & $40(14.93)$ & \\
\hline \multicolumn{6}{|c|}{ Is there anyone at home as microbiologist? } \\
\hline Yes & $7(2.30)$ & $0(0.00)$ & 0.51 & $0(0.0)$ & 0.28 \\
\hline No & $297(97.70)$ & $17(5.72)$ & & $42(14.14)$ & \\
\hline \multicolumn{6}{|c|}{ Is there anyone at home as veterinarian? } \\
\hline Yes & $2(0.66)$ & $0(0.00)$ & 0.73 & $0(0.0)$ & 0.56 \\
\hline No & $302(99.34)$ & $17(5.63)$ & & $42(13.91)$ & \\
\hline
\end{tabular}

Table 4 Seroprevalence of brucella IgM and IgG antibodies among pregnant women according to clinical symptoms associated with brucella infection

\begin{tabular}{llllll}
\hline Clinical symptoms & Participants & IgG positive & \multicolumn{3}{c}{ IgM positive } \\
\cline { 2 - 5 } & No. (\%) & No. (\%) & P-Value & No. (\%) & P-Value \\
\hline Fever & & & & \\
Yes & $140(46.05)$ & $7(5.00)$ & 0.68 & $18(12.86)$ & 0.65 \\
No & $164(53.95)$ & $10(6.10)$ & & $24(14.63)$ & \\
Undulant fever & & & & \\
Yes & $130(42.76)$ & $5(3.85)$ & 0.25 & $1 \mid(8.46)$ & $0.02^{*}$ \\
No & $174(57.24)$ & $12(6.90)$ & & $31(17.82)$ & \\
Anorexia & & & & \\
Yes & $164(53.95)$ & $10(6.10)$ & 0.68 & $21(12.80)$ & 0.58 \\
No & $140(46.05)$ & $7(5.00)$ & & $21(15.00)$ &
\end{tabular}


Table Continued...

\section{Weight loss}

Yes

No

Pain muscles

Yes

No

\section{Pain back}

Yes

No

Pain head back

Yes

No

\section{Coldness}

Yes

No

Headache

Yes

No

\section{Fatigue}

Yes

No

Sweaty

Yes

No

Cold

Yes

No

Delirium

Yes

No
240(78.95)

120(39.47)

184(60.53)

176(57.8)

I28(42.II)

234(76.97)

70(23.03)

I3 (43.09)

173(56.91)

64(21.05)

165(54.28)

139(45.72) 3(2.16)

207(68.09) II(5.3I)

97(31.91) 6(6.19)

85(27.96)

$219(72.04)$

153(50.33)

I5I(49.67)

$38(12.50)$

266(87.50)
5(4.17)

I2(6.52)

13(76.4)

4(23.5)

13(5.56)

4(5.7I)

$9(6.87)$

8(4.62)

15(6.25)

2(3.13)

|4(8.48)

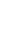

$0.01 *$

$28(16.97)$

I4(10.07)

0.76

29(14.0I)

I3(I3.40)

2(2.35)

0.12

9(10.59)

0.31

15(6.85)

33(I5.07)

$9(5.88)$

0.82

22(14.38)

0.77

8(5.30)

$0(0.00)$

17(6.39)
20(13.25)

0.12

2(5.26)

0.1

\section{Discussion}

This data is the first published data on the Seroprevalence of brucellosis among pregnant women in Yemen. Overly, the prevalence of brucella antibodies among pregnant women was 45 (15\%), Our findings were in close agreement with the previous study in Egypt (12.2\%) among pregnant women ${ }^{22}$ and in Rwanda $25 \%$ among women who suffered from abortions and stillbirth. ${ }^{23}$ While our findings were higher than the previous study among pregnant women reported in Iran (6.2\%). ${ }^{24}$ Pakistan $(5.8 \%),{ }^{20}$ Saudi Arabia (3.5\%), ${ }^{25}$ and Turkey $(3.7 \%){ }^{26}$ In this current study the seroprevalence of brucella IgG antibodies were $5.59 \%(17 / 304)$. The development of IgG antibody is an effort which is made by the immune system to help neutralize brucella. This antibody prolongs life and confers immunity against reinfection. So, it is correct to consider pregnant women who had IgG antibodies are immune.
A clearer picture was seen when the seroprevalence of $\operatorname{IgM}$ antibody to brucella was also considered. A prevalence of $13.82 \%$ for IgM antibody among pregnant women was obtained. Significantly, $4.6 \%$ of these subjects also had IgG antibody, suggesting that either reinfection or resolving primary infection and that they were not actually immune as concluded earlier, but were still in the recovery stage. In this present study, most of pregnant women were in their first trimester which found that women in the first trimester were $(4.44 \%$ and $12.59 \%$ for brucella IgG and IgM respectively). Vilchez et al., ${ }^{27}$ found higher rates of abortion in the first trimester while, Khan et al. ${ }^{28}$ found that the spontaneous abortion usually occurs in the second trimester.

In this current study, there is a significant association between brucella IgM seropositivity and urban area residence. Human brucellosis is found to have significant presence in rural/nomadic 
communities where people live in close association with animals. ${ }^{29}$ The reported incidence of human brucellosis in endemic disease areas varies widely, $<0.01$ to $>200$ per 100000 population. Brucellosis is still a main public health problem in developing countries. Endemicity in this region results from the persistence of domestic animals as reservoirs. People from third to fifth decades of life are most commonly affected. ${ }^{30}$ In urban areas, the main sources of brucella infection are slaughterhouses, dairies, laboratories conducting investigations handling live brucella cultures and veterinary institutions. ${ }^{31}$ Control by veterinarians of the disease in cattle, dogs, sheep, goats has substantially controlled brucellosis in humans. Mainly, the infection by Brucella abortus and Brucella suis are seen in people engaged in some aspects of the live-stock industries, whereas Brucella melitensis is primarily food borne and is associated with consumption of unpasteurized milk and milk products. ${ }^{30}$

The reproductive characteristics which have been studied in this research were not statistically significant with the presence of IgM or IgG antibodies. There were no previous studies which considered the association between the listed reproductive characteristics and risk of brucella infection. However, spontaneous abortion is defined as loss of pregnancy without outside intervention before 20 weeks of gestation. Up to $20 \%$ of the recognized pregnancies will end in spontaneous abortions. ${ }^{32}$ Infection of conceptus is one of the causes of abortion. Although brucellosis can result in human abortion, it is debated whether it is more frequent due to brucellosis than due to other bacterial infections. ${ }^{30}$ In our study, the result suggests that all reproductive characteristics studied are not significant predisposing factors to brucella infection or immunity. Our result was similar to study carried out in Jordon by Abo-Shehada et al., ${ }^{33}$ who found that there was no statistically significant difference between history of miscarriage and brucella infection. While, the results of study by (Elshamy et al., ${ }^{22}$ reported that there was a statistically significant difference in the incidence of abortion in pregnant women with brucella antibodies titre of more than 1/160 compared to those women with titre of less than $1 / 160$ (44.1 versus $19.4 \%$, respectively, $P$ value $0.03)$.

There was no statistically significant association between all possible risk factors and brucella infection. Although, many people in Yemen keep livestock in and around the family home with family members tending goats, sheep and sometimes cattle. They live in close proximity to their livestock which may be kept in the lower floor of the home, consume untreated milk and make laban (buttermilk) using unhygienic methods. Milk and laban are sold to the consumer directly or through groceries in cities and towns. In previous studies conducted in Yemen on human brucellosis showed that significant risk factors for brucella infection related to farmer, shepherd, as occupation, and microbiologist. ${ }^{34}$ But, the highly significant risk factors for infection were related to be associated with ownership of livestock animals, ${ }^{19}$ contact with clearing viscera of animals and placental membrane, ${ }^{18}$ and direct contact with their products (Handling new born, milking, and animal slaughter) and indirect contact with livestock (drinking unpasteurized milk, ${ }^{18,19,34}$ drinking laban, ${ }^{19,34}$ ingestion of local chees, raw liver and raw spleen). ${ }^{19}$ Brucellosis is sufficiently common in Yemen that specific public health measures are needed to combat this debilitating disease but these measures may need to be targeted at specific routes of infection among defined groups.

Many of the common clinical symptoms associated with brucella infection were observed in the pregnant women. Which included fever, headaches, lack of appetite, weight loss, fatigue, malaise, chills, sweats, myalgia, and arthralgia. ${ }^{8-11}$ In this findings, there were significant association with headache and undulant fever and the seropositivity for brucella IgG and IgM antibodies respectively. Most of pregnant women in this research made complaints of delirium. Few of these women were, positive for brucella (IgM antibody), suggesting that the delirium was due to other factors. The overall clinical picture of human brucellosis likewise was reported by other researchers in this geographical area. Another previous study in southern part of Yemen, ${ }^{35}$ studied 235 cases of human brucellosis in Sana'a city giving male: female ratio of $1.3: 1 \%$ respectively. This present study suggest that male and female exposure to the risk of brucella infection is about the same, and that the activities associated with exposure are performed by both sexes or that they are exposed to the same reservoir of infected animals but at different point in the cycle of contact.

\section{Limitations of the study}

Polymerase Chain Reaction (PCR) test of the bacterial DNA isolation was not used due to financial constraints.

\section{Conclusion}

The overall seroprevalence of brucella antibodies was high. This is suggesting that a sustained infection in the Yemeni population and indicating endemicity. Adoption of brucella screening into the antenatal profile tests is recommended for early detection and treatment. Advance study intended to compare all provinces in the country with brucella seroprevalence in order to get comprehensive information of the problem is recommended.

\section{Acknowledgements}

We acknowledge contribution of all women in science, who support and contribute in this study. This research work was supported Department of Biology, Faculty of Science, Sana'a University, Sana'a, Yemen. We are also grateful to Al- Thobhani Modern Medical Laboratory, Sana'a, Yemen for their cooperation.

\section{Conflict of interest}

The author declares no conflict of interest.

\section{References}

1. Corbel M, Elberg S, Cosivi O. Brucellosis in humans and animals World Health Organization. Geneva Open URL; 2006.

2. Grimont F, Verger JM, Cornelis P. Molecular typing of brucella with cloned DNA probes. Res Microbiol. 1992;143(1):55-65.

3. Moreno E, Stackebrandt E, Dorsch M, et al. Brucella abortus 16S rRNA and lipid A reveal a phylogenetic relationship with members of the alpha-2 subdivision of the class Proteobacteria. J Bacteriol. 1990;172(7):35693576.

4. Boschiroli ML, Foulongne V, O'Callaghan D. Brucellosis a worldwide zoonosis. Curr Opin Microbiol. 2001;4(1):58-64.

5. Chen S, Zhang H, Liu X, et al. Increasing threat of brucellosis to low-risk persons in urban settings, China. Emerg Infect Dis. 2014;20(1):126-130.

6. Mesner O, Riesenberg K, Biliar N, et al. The many faces of human-tohuman transmission of brucellosis:congenital infection and outbreak of nosocomial disease related to an unrecognized clinical case. Clin Infect Dis. 2007;45(12):135-140. 
7. Peker N, Volkan T, Mete E, Ozgur Y. Brucellosis in adolescent pregnancycase report and review of literature. Ginekol Pol. 2011;82(3):226-229.

8. Ali S, Ali Q, Neubauer H, Melzer F, et al. Seroprevalence and risk factors associated with brucellosis as a professional hazard in Pakistan. Foodborne Pathog Dis. 2013;10(6):500-505.

9. Dames S, Tonnerre C, Saint S, et al. Clinical problem solving. Don't know much about history. N Engl J Med. 2005;352:2338-2342.

10. Dean AS, Crump L, Greter, $=\mathrm{H}$, et al. Clinical manifestations of human brucellosis:a systematic review and meta-analysis. PLoS Negl Trop Dis. 2012;6(12):10-12.

11. Young EJ. Clinical manifestations of human brucellosis. Boca Raton CRC press; 1989;97:126.

12. Eyre JWH. Melitensis septicemia. Lancet. 1908;5:1747-1752.

13. Seoud M, Saade G, Awar G, et al. Brucellosis in pregnancy. J Reprod Med. 1991;36:441-445.

14. Young EJ. Human brucellosis. Rev Infect Dis. 1983;5(5):821-842.

15. Poole PM, Whitehouse DB, Gilchrist MM. A case of abortion consequen upon infection with Brucella abortus biotype 2. J Clinl Pathol. $1972 ; 25(10): 882-884$.

16. Brucellosis in humans and animals. WHO; 2006

17. Al-Arnoot S, Abdullah QYM, Alkhyat SH, et al. Human and Anima Brucellosis in Yemen. J Hum Virol Retrovirol. 2017;5(4):00162.

18. Nasher AAM. Brucellosis in human associated with animals in Sana'aYemen and in laboratory prepared antigen for antibody detected. Msc thesis. Department of Microbiology, Faculty of Medicine and Health Sciences, Yemen: Sana'a University; 2006.

19. A1-Haddad AM, A1-Madhagi A, Talab AA, et al. Prevalence of human brucellosis in three selected areas at Al-Dhala'a Governorate, Yemen. Msc thesis. Department of Microbiology, Faculty of Medicine and Health Sciences, Sana'a University, Yemen: Faculty of Science Bulletin, Sana'a University; 2013;25:61-71.

20. Ali S, Akhter S, Neubauer H, et al. Brucellosis in pregnant women from Pakistan: an observational study. BMC Infect Dis. 2016;16(1):468.

21. Saleh NAA. Seroprevalence of brucellosis among slaughterhouse workers in the Republic of Yemen. Msc thesis. Department of Microbiology, Faculty of Medicine and Health Sciences, Yemen: Sana'a University; 2000
22. Elshamy M, Ahmed AI. The effects of maternal brucellosis on pregnancy outcome. J Infect Dev Ctries. 2008;2(3):230-234.

23. Rujeni N, Mbanzamihigo L. Prevalence of brucellosis among women presenting with abortion/stillbirth in Huye, Rwanda. Journal of Tropical Medicine. 2014;740479:3

24. Salari MH, Khalil MB, Hassanpour GR. Selected epidemiologic features of human brucellosis in Yazd, Islamiv Republic of Iran (1993-1998). East Mediterr Health J. 2003;9:5-6.

25. Sharif A, Reyes Z, Thomassen P. Screening for brucellosis in pregnant women. J Trop Med Hyg. 1990;93(1):42-43.

26. Fevziye C, M Nacer N, Koc AN, et al. Prevalence of brucellosis in the rural areas of Kayseri, Central Anatolia, Turkey. Turk J Med Sci. 2005;35:121-126.

27. Vilchez G, Espinoza M, D’Onadio G, et al. Brucellosis in pregnancy: clinical aspects and obstetric outcomes. Int J Infec Dis. 2015;38:95-100.

28. Khan MY, Mah MW, Memish ZA. Brucellosis in pregnant women Brucellosis in pregnant women. Clin Infect Dis. 2001;32(8):1172-1177.

29. Boschiroli M-L, Foulongne V, O’Callaghan D. Brucellosis: a worldwide zoonosis. Curr Opin Microbiol. 2001;4(1):58-64.

30. Puri M, Patel N, Gaikwad V, et al. A Study of Prevalence of Brucellosis in Cases of Spontaneous Abortions. RJPBCS. 2015;6(3):312-320.

31. Castaneda MR. Laboratory diagnosis of brucellosis in man. Bull World Health Organ. 1961;24(1):73-84.

32. Griebel CP, Halvorsen J, Golemon TB, et al. Management of spontaneous abortion. Am Fam Physician. 2005;72(7):1243-1250.

33. Abo-Shehada MN, Abu-Halaweh M. Seroprevalence of Brucella species among women with miscarriage in Jordan. East Mediterr Health J. 2011;17(11):871-874.

34. Al- Shamahy H, Whitty CJM, Wright SG. Risk factors for human brucellosis in Yemen:a case control study. Epidemiol Infect. 2000;125(2):309-313.

35. Al- Shamahy H, Wright SG. A study of 235 cases of human brucellosis in Sana'a, Republic of Yemen. East Mediterr Health J. 2001;7(1-2):238246. 